\title{
INTERthesis
}

\section{A PSICOLOGIA SOCIAL SOCIOLÓGICA: PERCURSOS, RUMOS E CONTEMPORANEIDADE DE UMA TRADIÇÃO TEÓRICO-METODOLÓGICA}

\section{Resumo:}

Rita de Cássia Fazzi ${ }^{1}$

Jair Araujo de Lima²

O artigo pretende realizar a tarefa de revisitar a história de uma tradição sociológica que nasceu e se desenvolveu enquanto psicologia social direcionada ao estudo dos indivíduos em interação e que postula uma concepção do "sujeito" como agente capaz e reflexivo, que em todo tempo inventa e reinventa a si mesmo, povoando os cenários sociais, formando e transformando a realidade social. A tradição da psicologia social sociológica inicia-se na França com Tarde e Le Bon e foi institucionalizada nos Estados Unidos, consistindo no efetivo modelo de sociologia praticada em seus primeiros anos naquele país. Dessa tradição fazem parte a Escola de Chicago e o Interacionismo Simbólico.

Palavras-chave: Psicologia Social Sociológica. História da Sociologia. História da Psicologia Social. Interacionismo simbólico.

\section{INTRODUÇÃO}

A sociologia e a psicologia social não são somente dois campos científicos cujos temas e objetos são transversalmente abordados em cada topos da divisão do trabalho científico, não são unicamente disciplinas cujos problemas e objetos de estudo estão circunscritos na mesma fronteira do saber científico "humanista" (JACÓ-VILELA; FERREIRA; PORTUGAL, 2006; ABIB, 2009)33, também não são programas científicos que rivalizam os seus achados e/ou seguem independentemente ou cujos pesquisadores possam desconsiderar as descobertas e produções em cada um desses campos nos seus respectivos trajetos e tradições de pesquisa.

Se bem que alguns adeptos de uma e outra perspectiva de pesquisa, reincidentemente, insistam em focar somente nos problemas, limitações ou

\footnotetext{
${ }^{1}$ Doutora em Sociologia pelo Instituto Universitário de Pesquisas do Rio de Janeiro, Rio de Janeiro, RJ, Brasil. Professora do Programa de Pós-Graduação em Ciências Sociais da Pontifícia Universidade Católica de Minas Gerais, Belo Horizonte, MG, Brasil. E-mail: rfazzi@pucminas.br

2 Mestrando em Ciências Sociais pela Pontifícia Universidade Católica de Minas Gerais, Belo Horizonte, MG, Brasil. Bolsista do(a): Fundação de Amparo à Pesquisa do Estado de Minas Gerais. E-mail: jairpopper@hotmail.com

${ }^{3}$ Evidentemente, desde Willian James (1814-1910), existe um "apelo para que a psicologia seja [concebida como] uma ciência natural". Este é o título de um artigo escrito por Willian James (Cf. JAMES, 2009).
}

R. Inter. Interdisc. INTERthesis, Florianópolis, v.13, n.3, p.101-120 Set.-Dez. 2016 
extrapolações (psicologismo e sociologismo) ${ }^{4}$ de cada lado da fronteira epistemológica - que inclusive estão na intersecção das rivalidades históricas entre a psicologia e a sociologia puras (MUNNÉ, 1993, 1996) - há, para além da relação interdisciplinar que ocorre contemporaneamente, e desde suas origens, entre essas disciplinas irmãs, uma relação histórica e inextricável que as relaciona absolutamente: a relação de "paternidade" que as constitui (MENDRAS, 1975; ALVARO; GARRIDO, 2007; FARR, 2010).

Não é difícil, ao pesquisador iniciante ou ao estudante curioso, perceber as origens comuns da sociologia e da psicologia social, tanto nos termos de problemas de pesquisa e objetos de estudo, quanto na perspectiva da "paternidade" teórica por aqueles que as criaram, dando-lhes status de cientificidade, e que fomentaram a sua separação em fronteiras epistemológicas tradicionalmente diferentes e, às vezes, divergentes. $O$ fato, fácil de constatar, e que queremos dar ênfase neste trabalho, é que os chamados "pais" dessas duas tradições de pesquisa humanísticas foram tanto sociólogos quanto psicólogos.

Factualmente, a psicologia e a sociologia foram pensadas como "novas ciências" nos escritos dos próprios fundadores da sociologia (, 1966; ESTRAMIANA et al., 2007), como Saint-Simon (1760-1825), Augusto Comte (1798-1857), Herbert Spencer (1820-1903), Gabriel Tarde (1843-1904) e, mesmo, Émile Durkheim (18581917). Este último, polemizando com Tarde (CONSOLIM, 2007, 2010), escreveu em seu "O Suicídio" (1897) sobre o lugar da também nascente psicologia social nos estudos dos fenômenos da coletividade.

Uma tradição que vem desde Herder (1744-1803) que via o "volks" como uma "comunidade [ou mentalidade] cultural", Hegel (1770-1831) que fala de "espírito coletivo [dos povos]" (Volksgeist) e Herbart (1776-1841) que fala de um "espírito do todo [coletivo]" (Allgeist), demarca as origens metafísicas da psicologia social. As primeiras versões empiristas da psicologia tiveram David Hume (1711-1776) como pioneiro. Embora sua análise empirista dos "sentimentos" seja, de fato, eivada de metapsicologia, que bem entendida consiste numa psicologia metafísica. Contudo, as suas duas obras "Tratado da natureza humana" (1739) e "Investigação sobre o entendimento humano" (1748) forneceram argumentos empiristas para o

\footnotetext{
${ }^{4}$ Munné (1993) fala-nos que "os velhos e constantes 'fantasmas' da psicologia social [...] [são] [...] o psicologismo e o sociologismo." (p.72). Se o psicologismo consiste numa redução descabida do social ao psicológico, o sociologismo demarca uma redução indevida do psicológico ao social.
}

R. Inter. Interdisc. INTERthesis, Florianópolis, v.13, n.3, p.101-120 Set.-Dez. 2016 
associacionismo e demarcaram o início da busca por uma psicologia empírica. (Cf. MUNNÉ, 1993).

Adam Smith (1723-1790) segue o caminho de Hume ao publicar a sua "The Theory of Moral Sentiments" (1759) e oferecer mais argumentos ao associacionismo. Smith influencia os utilitaristas, os quais, posteriormente, tornaramse os principais estudiosos das "influências recíprocas" entre os indivíduos no convívio social. Alexander Bain (1818-1903), discípulo de Stuart Mill (1806-1873), escreve "The senses and the intellect" (1855) e, em seguida, "The emotions and the will" (1859) $)^{5}$. Essas obras - classificadas como sendo "psicologia associativa" defendem a perspectiva de que a interação dos indivíduos influencia tanto o seu comportamento social quanto as estruturas por eles criadas, inclusive as estruturas das percepções sobre a ética e estética (Cf. ALVARO; GARRIDO, 2007).

Somente um ano após a publicação de Bain, dois autores filiados à escola de Herbart - Moritz Lazarus (1824-1903) e Hermann Steinthal (1823-1899) - fundam a uma revista científica intitulada "Zeitschrift für völkerpsychologie und sprachwissenschaft [Jornal de Psicologia dos Povos e Estudo da Língua]" em 1860. Nessa revista eram publicados tanto trabalhos teóricos como de investigação empírica ou experimental (Cf. ALVARO; GARRIDO, 2007; FARR, 2010).

A proposta de revista é significativa, pois, por um lado, assume - na linha tanto dos utilitaristas, sobretudo de Bain, que falavam de uma "psicologia associativa" quanto de Herbart que falava das "representações coletivas" 6 - que as entidades "supraindividuais" de tipo grupal, ou fenômenos de "agregação", também poderiam ser objeto de estudo psicológico e este é, precisamente, o posicionamento basilar da incipiente psicologia social. Por outro lado, a revista associa dois aspectos que seriam amplamente abordados pela também nascente sociologia alemã, que são a sociabilidade ${ }^{7}$ e a comunicação interativa.

\footnotetext{
${ }^{5}$ Alexander Bain será ainda, em 1876, o editor fundador da revista "Mind" (FARR, 2010).

6 (1966) informa que Herbart e os alemães falam de "representações coletivas" antes de Durkheim. Boudon e Bourricaud (1993b [1982]) afirmam que é de Spencer que Durkheim empresta - embora este não reconheça - a atenção aos fenômenos de "agregação" social e das "representações coletivas" como um fenômeno de agregação das representações individuais.

7 Noção refinada por Georg Simmel, mas já presente nos primeiros estudos da psicologia social alemã. A diferença é que o conceito de sociabilidade dos pesquisadores de psicologia coletiva alemães era usado no sentido que Simmel dá a sociação. É da sociação que Simmel deriva o seu aprimorado conceito de sociabilidade como sendo uma "forma lúdica da sociação" (SIMMEL, 2006, p. $65)$.
} 
Alguns anos antes - até mesmo, de Wilhelm Wundt (1832-1920) ter fundado em 1879 em Leipzig o primeiro laboratório de psicologia experimental, em que se preocuparia em estudar os conteúdos da mente individual -, podemos encontrar outros cientistas adotando, como objeto dos estudos psicológicos, várias formas da mentalidade coletiva. O próprio Wundt cavou em ambos os campos, uma vez que publicou um trabalho com o título "Völkerpsychologie [psicologia dos povos]" (19001920) em 10 volumes e cuja versão sincrônica (FARR, 2010, p.211) "Elemente der völkerpsychologie" (1912) viria a impressionar tanto a Freud (1856-1939), ao escrever "Totem e Tabu" (1913)', quanto aos pesquisadores anglo-saxões (psicólogos, sociólogos e antropólogos) a partir de sua tradução "Elements of folk psychology" (1916).

A figura de Wundt - seu papel intelectual e institucional para a psicologia empírica - impressiona Durkheim quando este, em visita a universidades europeias entre 1885 e 1886, o conhece pessoalmente em Leipzig (FARR, 2010, p.207). Com efeito, Durkheim não somente inspirou-se nos escritos de Wundt, mas também, a partir de sua experiência em Leipzig, buscou seguir o projeto intelectual de Wundt, isto é, o de instucionalização de sua disciplina (Cf. CLARK, 1968; ORTIZ, 1989). ${ }^{9}$

É notável a influência de Wundt sobre Durkheim. Influência esta não reconhecida formalmente por Durkheim, mas perceptível no caso particular que mencionamos a seguir. Em 1897 Wundt postula em seu "Grundriss der psychologie" $(1897)^{10}$, o princípio dos resultantes criativos ou aquilo que Spencer (Cf. BOUDON; BOURRICAUD, 1993b [1982]) denominou fenômenos de agregação. Em sua formulação dos princípios de uma psicologia empírica, Wundt argumenta, nas palavras de Abib (2009), que: "De acordo com o princípio dos resultantes criativos, não é possível predizer, tomando-se por base o conhecimento dos processos psíquicos componentes, as qualidades dos processos psíquicos resultantes" (p.198). Nos termos de Wundt: "em todas as combinações psíquicas o produto não é a mera soma dos elementos que compõem tais combinações, mas representa uma nova

\footnotetext{
8 Livro no qual iremos encontrar uma referência a Durkheim.

9 Ortiz (1989) também aponta para o fato de que essa experiência de Durkheim não deve ser subestimada por qualquer um que pretenda estudar o processo - implementado por Durkheim - de institucionalização da sociologia na França.

10 A tradução inglesa desta obra é: WUNDT, Wilhelm. "An introduction to psychology". London: George Allen \& Company, Ltd.,1973 [1912].
} 
criação" (WUNDT, 1973 [1912], p. 164 apud ABIB, 2009, p.198). ${ }^{11}$ Deste modo, o fenômeno global emerge como uma coisa nova - sui generes - uma vez que suas qualidades resultantes, uma vez agregadas, não estão contidas na individualidade dos elementos que o compõem.

Durkheim, em 1898, em seu "Représentations individuelles et représentations collectives" (1898), estabelece para o "fato social", que neste caso são as "representações coletivas", o mesmo modelo argumentativo que o dos princípios dos resultantes criativos utilizado por Wundt para as combinações psíquicas, como segue:

Se podemos dizer, em certo sentido, que as representações coletivas são exteriores às consciências individuais, é porque elas não derivam dos indivíduos tomados isoladamente, mas de seu concurso. $\mathrm{O}$ que é bem diferente. Sem dúvida, na elaboração do resultado comum, cada um tem a sua contribuição; mas os sentimentos privados se tornam sociais somente ao se combinar sob a ação de forças sui generis que a associação desenvolve; em consequência dessas combinações e das alterações mútuas que daí resultam, eles se tornam outra coisa (DURKHEIM, 2009 [1898], p.39, grifo original).

É, portanto, na fonte de Wundt que Durkheim vai beber para montar o seu arsenal argumentativo contra as teses da psicologia social de Tarde, naquelas "batalhas importantes pela ordenação das hierarquias disciplinares e, principalmente, pela definição da disciplina hegemônica" (CONSOLIM, 2007, p.02).

\section{GABRIEL TARDE E A PSICOLOGIA SOCIAL}

Consideradas, portanto, as contribuições filosóficas de Herder, Herbart e Hegel, as da "psicologia associativa" dos utilitaristas, aquelas da "psicologia dos povos" iniciada por Lazarus e Steinthal na Alemanha em 1860, as da "escola das correntes coletivas" iniciada por Walter Bagehot (1826-1877) na Inglaterra com sua obra "Phisics and politics" (1872), a de Charles Darwin (1809-1882) com seu "The expression of emotion in man and animal (1972), a de Herbert Spencer (1820-1903) com seu conceito de "fenômenos de agregação" e, finalmente, dos estudos de psicologia cultural de Wundt iniciados em 1879, a psicologia social em seu formato clássico nasce, na França, sob a influência dos sociólogos Gabriel Tarde (18431904) e Gustave Le Bon (1841-1931).

\footnotetext{
${ }^{11}$ A obra da qual Abib (2009) estrai esta citação é: WUNDT, Wilhelm. An introduction to psychology. London: George Allen \& Company, Ltd.,1973 [1912].
}

R. Inter. Interdisc. INTERthesis, Florianópolis, v.13, n.3, p.101-120 Set.-Dez. 2016 
Com efeito, é a Gabriel Tarde que tem sido amplamente creditada a paternidade da psicologia social sociológica, em seus moldes clássicos. Henri Mendras (1975) não somente afirma que Gabriel Tarde foi o "fundador da Psicologia Social" (p.13), como também defendeu que "devemos entender por Sociologia simultaneamente a Sociologia, a Psicologia Social e a Etnologia". (p.09). No entanto, essas três disciplinas constituem tradições próprias de pesquisa e cada uma delas abriga diferentes tradições teóricas. Mas, junto com Mendras (1975), não devemos esquecer as origens comuns dessas disciplinas.

Sustenta-se, entre os historiadores da psicologia social (JACÓ-VILELA; FERREIRA; PORTUGAL, 2006; FARR, 2010), que o marco do surgimento da psicologia social como disciplina independente e moderna foi a publicação (nos EUA) dos dois primeiros handbooks da disciplina por iniciativas, por um lado, do sociólogo Edward A. Ross (1866-1951) - com seu "Social psychology: an outline and a source book" (1908), o qual segue a linha tardeana de psicologia social e estuda os fenômenos de imitação, de sugestão e da simpatia ${ }^{12}$ - e, por outro lado, do psicólogo Willian McDougall (1871-1938) com o seu "An introduction to social psychology" (1908); o qual, embora não desconsidere a importância dos três elementos tardeanos da conduta social, introduziu a ação do "instinto" no comportamento social dos indivíduos. Note-se que esses dois manuais foram publicados no ano de 1908. Enquanto Mcdougall mostra-se influenciado pela Völkerpsychologie de Wundt, Ross sofre a influência de Weber, Simmel e Cooley. Álvaro-Estramiana e Garrido-Luque (2007) observam que: "Enquanto o texto de Ross está centrado nas explicações de causas sociais que ocasionam as uniformidades do comportamento, para McDougall o que há a explicar são as bases instintivas da conduta humana" (p.13).

Farr (2010) argumenta que a psicologia social moderna consiste num "fenômeno caracteristicamente americano" (p.19) estando ligado, desde os seus primeiros anos, tanto à Escola de Chicago quanto ao interacionismo simbólico e, por fim, aponta George Herbert Mead (1863-1931) como o fundador da psicologia social em seus aspectos modernos. Em razão disso, Farr (2010) dedica a Mead o quarto capítulo de seu livro sobre as raízes desta área intersectiva. Além disso, tanto Farr

12 Tão tardeano que "um historiador americano da sociologia diz que este volume "pode ser considerado, em parte, como uma tradução livre de passagens do Les lois de l'imitation, de Tarde." (HOUSE,1936, p.320 apud BRAMSON, 1963, p. 71).

R. Inter. Interdisc. INTERthesis, Florianópolis, v.13, n.3, p.101-120 Set.-Dez. 2016 
(2010) quanto Mendras (1975) apontam a influência de Gabriel Tarde, não somente sobre Ross, mas em toda a incipiente sociologia americana, bem como na nascente psicologia dos EUA. Alvaro e Garrido (2007) enunciam que foram as obras de Tarde que inauguraram a disciplina e que - assim como Durkheim na sociologia, com o seu "As regras do método sociológico" (1895) - Tarde é, com sua "Les lois de l'imitation" (1890), e seu "Études de psychologie sociale" (1898) o fundador da psicologia social enquanto ciência autônoma e independente da biologia e da filosofia.

Alvaro e Garrido (2007) observam que o primeiro handbook de sociologia publicado - "An introduction to the study of society" (1894) de Albion Small e George E. Vincent - a psicologia social é abordada em cinco capítulos. Essa obra é fruto da iniciativa de Albion Small (19854-1926), o fundador do departamento de sociologia na Universidade Chicago (em 1892) e da revista de sociologia American Journal of Sociology em 1895 (COULON, 1995). Alvaro e Garrido (2007) dão-nos indícios sobre o fato de que a sociologia americana - que nasce influenciada por Tarde, Simmel e Weber - emerge no cenário universitário dos EUA como psicologia social.

Gordon W. Allport (1897-1967) escreve que: "Embora as raízes da psicologia social possam ser encontradas no solo intelectual da tradição ocidental, seu atual florescimento é reconhecido como sendo um fenômeno caracteristicamente americano" (ALLPORT,1954 apud FARR, 2010, p.19) ${ }^{13}$. Sendo, isso, fato, podemos ter uma certeza robusta de que a sociologia (nos EUA) teve grande contribuição neste aspecto da transformação americana da psicologia social. Do mesmo modo que na França, onde a psicologia social surge em seu aspecto pré-moderno, nos EUA a psicologia social - em seus primeiros movimentos - nasce da sociologia.

Se Coser (1980, p. 384ss) e Coulon (1995) afirmam - cada um em seus próprios termos - que durante cerca de 30 anos, desde seu florescimento no solo universitário dos EUA, a sociologia americana foi sinônimo de Escola de Chicago; podemos afirmar que, durante esses mesmos cerca de 30 anos, a sociologia praticada nos Estados Unidos foi uma forma do que hoje é denominado por psicologia social sociológica (FARR, 2010). Neste contexto, sabe-se que tanto a Escola de Chicago (EC) quanto o Interacionismo Simbólico (IS) contribuíram para a

13 O texto citado por Farr (2010) constam em: ALPORT, Gordon W. The historical background of modern social psychology. In: LINDZEY, G.; ARONSON. E. (Org.). Handbook of Social Psychology. 3.ed.. Vol.1. New York: Random House, 1954, p.01-46.

R. Inter. Interdisc. INTERthesis, Florianópolis, v.13, n.3, p.101-120 Set.-Dez. 2016 
implementação de métodos inovadores de pesquisa para as ciências sociais (GOLDENBERG, 2004). É farta a literatura que reconhece a EC e o IS como desenvolvedores de métodos originais de investigação direcionados à pesquisa qualitativa. Chaves e Borges (2005), por exemplo, confirmam que "foi no campo da Psicologia Social sociológica que a investigação qualitativa e os estudos de campo tiveram maior influência [...] [e] [...] uma maior pluralidade metodológica" (p.322).

Torna-se necessário apontar as fontes da EC e do IS, uma vez que ambos são programas de psicologia social sociológica. Seu contexto sociológico, pode ser observado, certamente, pelo exame das trajetórias biográficas dos pesquisadores relacionados às duas correntes que demarcam momentos históricos diferentes na Universidade de Chicago (Cf. COULON, 1995). Albion W. Small, por exemplo, como fundador do primeiro departamento de sociologia do mundo (1892), da segunda revista de sociologia da história - dois anos depois da Revue Internationale de Sociologie (1893) de René Worms [1869-1926] (Cf. ORTIZ, 1989, p. 10; COULON, 1995) - e do primeiro manual de sociologia da história, escrito em 1894 (ALVARO; GARRIDO, 2007, p.40), deve figurar, com justiça, como um dos fundadores da sociologia, uma vez que - sob a sua influência - certos aspectos da sociologia, nos Estados Unidos, receberam contribuições originais (Cf. COSER, 1980; EUFRÁSIO 1999). Como o estudo das biografias revela certos aspectos do contexto sociológico no qual estão imersos os atores, é significativo o fato de que Small foi tanto colega de estudos de Georg Simmel em Berlim (COULON, 1995) e amigo de Max Weber ${ }^{14}$, quanto foi - junto com Robert E. Park, Edward Ross e James Mark Baldwin - um dos tradutores e divulgadores da obra de Gabriel Tarde nos Estados Unidos (Cf. BRAMSON,1963 p.63ss).

Apontamos a seguir, a EC e o IS como sendo tradições sociológicas em que os temas e as metodologias fundamentais da nascente psicologia social sociológica (PSOsocio) se desenvolvem. Contudo, não podemos deixar de fazer quatro ressalvas. A primeira é que em sua primeira fase, a EC - como uma sociologia urbana - é globalmente influenciada por Émile Durkheim, embora não deixe de citar as contribuições de Tarde. Em segundo lugar, embora o IS elaborado por Herbert Blumer tenha assumido uma postura de oposição à sociologia durkheimiana e ao

14 "[...] foi Small quem trouxe Max Weber e Gustav Ratzenhoffer para o Congresso de Artes e Ciências de 1904, em Saint Louis [EUA]" (EUFRÁSIO, 1999, p.32).

R. Inter. Interdisc. INTERthesis, Florianópolis, v.13, n.3, p.101-120 Set.-Dez. 2016 
estruturalismo, um Interacionismo Simbólico Estrutural (Cf. GONOS, 1977; STRYKER, 1987, 2008) que assume proprosições durkheimianas emergiu sob a influência de Sheldon Stryker (1924-2016) e Erving Goffman (1922-1982). Em terceiro lugar, a sociologia elaborada por Talcott Parsons (1902-1979) é amplamante compreendida como sendo uma forma de psicologia social sociológica (Cf. ESTRAMIANA, et. al., 2007; ALVARO; GARRIDO, 2007; FARR, 2010). O modelo de psicologia social de Parsons é globalmente fundamentado nas formulações de Durkheim, o que Parsons assume textualmente (Cf. PARSONS, 1949). Por fim, embora se possa afirmar que os primeiros desenvolvimentos da psicologia social sociológica sejam amplamente creditados à influência de Tarde, os desenvolvimentos contemporâneos da PSOsoc são devedores à influência de Durkheim. A Teoria das Representações Sociais (TRS) de Serge Moscovici (19282014) tem sua fonte no conceito de "representações coletivas" tal como elaborada por Durkheim (Cf. MOSCOVICl, 2000, 2011). Assim, é meramente em função do nosso escopo para este artigo que estamos enfatizando o período de surgimento da PSOsoc e as contribuições da EC e do IS. As contribuições da PSOsoc de influência durkheimiana - como a TRS (Cf. ALMEIDA, 2009) - é mundialmente reconhecida e como imensa repercussões no Brasil.

\section{A ESCOLA DE CHICAGO (EC) E O INTERACIONISMO SIMBÓLICO (IS):}

A escola sociológica de Chicago - após a sua fase de ecologia urbana liderada por Robert E. Park (1864-1944) e Ernest W. Burgess (1886-1966) e que teve contribuições de pesquisadores renomados como Louis Wirth (1897-1952), Everett C. Hughes (1897-1983), Roderick D. McKenzie (1885-1940) - entrou em sua fase interacionista pela liderança de Herbert Blumer (1900-1987), o qual resgatou a tradição psicossociológica dos primeiros anos dessa comunidade intelectual e que está presente nos escritos dos seus pesquisadores pioneiros como William I. Thomas (1863-1947), Florian W. Znaniecki (1882-1958) e, sobretudo, G. H. Mead (1863-1931). Com efeito, como destaca González Rey (2009): "A proposta de psicologia social desenvolvida por Mead encontra sua continuação na sociologia, com o interacionismo simbólico" (p.77).

Conforme Blumer (1969), o IS fundamenta-se em três premissas fundamentais: 
1) Os seres humanos atuam no mundo e o interpretam amparados nos significados que este lhes oferece;

2) Tais significados são provenientes da ou provocados pela interação social que se mantém com as demais pessoas;

3) Os significados são manipulados por um processo hermenêutico utilizado pelo agente ao se relacionar com os elementos (pessoas, coisas, etc.) com os quais entra em contato.

Uma das implicações do IS na pesquisa sociológica é sua teoria da ação e sua afirmação explícita da competência do indivíduo, enquanto sujeito, de transformação das estruturas sociais sempre em mudança. Com efeito, "Blumer vê as pessoas, a ação organizada e o meio como fluxos continuamente construídos e reconstruídos via processos definitórios e interpretativos" (BAZILLI et al., 1998, p.31). Desta maneira, a corrente interacionista simbólica veio a contribuir para a criação e institucionalização da psicologia social nos estados unidos e consolidou-se como sendo a principal corrente sociológica da psicologia social (PORTUGAL, 2006; ALVARO; GARRIDO, 2007).

Já deixamos evidente, até aqui, que a psicologia social sociológica não surge com o IS, ela emerge do debate Durkheim versus Tarde (Cf. CONSOLIM, 2007, 2008, 2010), contexto no qual Émile Durkheim (1858-1917) insiste em que o nome da ciência social nascente deveria ser sociologia, ao passo que Tarde insistira que a nova ciência deveria ser denominada psicologia social. Durkheim, com todos os seus méritos intelectuais - mas não desprovido de artifícios institucionais (Cf. ORTIZ, 1989; VARGAS, 2000) - vence o embate. Tarde, no entanto, tanto inaugurou o debate sobre a psicologia social na Europa quanto permaneceu chamando a sua prática teórica pelo nome de psicologia social. Cabe a Durkheim o mérito da fundação da sociologia como ciência autônoma e a Tarde o de fundação da psicologia social como campo correlato à sociologia na França.

Também já evidenciamos que Simmel e Weber foram teóricos que influenciaram amplamente os sociólogos da Escola de Chicago e que é pouco mencionado, porém, o fato de que Gabriel Tarde tenha também exercido influência sobre os primeiros sociólogos norte-americanos e, sobretudo, sobre os pioneiros da Escola de Chicago (ALVARO; GARRIDO, 2007; FARR, 2010). Tal fato, antes mesmo de Durkheim - cuja obra seria divulgada nos Estados Unidos por iniciativa 
de Talcott Parsons - começar a influenciar a sociologia norte-americana e o interacionismo posterior, como o de Goffman e Stryker.

Com efeito, a sociologia da interação ou "microssociologia" de Tarde foi uma fundamental influência na nascente sociologia norte-americana, em sociólogos pioneiros como Charles H. Cooley (1864- 1929) e Edward A. Ross (1866-1951), encontrando eco tanto nos trabalhos dos pioneiros da sociologia de Chicago quanto em autores da psicologia como William Mcdougall (1871-1938) e Gordon W. Allport $(1897-1967)^{15}$.

Se o debate fundamental entre Durkheim e Tarde inscreveu-se na questão sobre "o que é o social e qual a sua especificidade?", tal problemática redunda com a imediata hegemonia da perspectiva durkheimiana na França e com a aceitação e divulgação da perspectiva de Tarde no EUA (Cf. ORTIZ, 1989; VARGAS, 2000) - em duas formas diferentes de se fazer sociologia. Cada uma das perspectivas apontando para polos diferentes na relação de constituição e influências dos dois elementos que compõem as temáticas clássicas tanto da sociologia quanto da psicologia social: a relações entre o micro e macro, entre o indivíduo e a sociedade, entre a personalidade e a estrutura, entre a subjetividade e a cultura.

É, portanto, nos Estados Unidos que a perspectiva sociológica de Tarde encontra ecos e adeptos ${ }^{16}$. Os escritos de Tarde estão entre as obras e perspectivas que influenciaram significativamente a fecunda tradição sociológica norte-americana amplamente conhecida como Escola de Chicago, bem como os desdobramentos posteriores da pesquisa em psicologia social na terceira fase ${ }^{17}$ da $\mathrm{EC}$, a não menos fecunda tradição de pesquisa sociológica designada pelo nome de Interacionismo Simbólico, corrente da sociologia norte-americana sobre a qual um de seus prolíficos autores pôde afirmar: "Nesta corrente sociológica, a 'psicologia social' nunca fora

15 O irmão de Gordon W. Allport, Floyd Henry Allport (1890-1978) é o responsável pelo giro experimental na psicologia social.

${ }_{16} \mathrm{Na}$ Itália, Vilfredo Pareto (1848-1923) foi um acolhedor da obra de Tarde e se tornou um dos autores clássicos da "sociologia psicológica" (Cf. TIMASHEFF, 1978, pp.201-209).

17 A primeira fase da Escola de Chicago é conhecida como ecologia humana (liderada por Albion Small [1854-1926] e William I. Thomas [1863-1947]), a segunda fase ficou conhecida como ecologia urbana (liderada por Robert E. Park [1864-1944] e Ernest W. Burgess [1886-1966]) e a terceira fase denominou-se interacionismo simbólico (liderada por Herbert Blumer [1900-1987]) (Cf. COULON, 1995, EUFRASIO, 1999).

R. Inter. Interdisc. INTERthesis, Florianópolis, v.13, n.3, p.101-120 Set.-Dez. 2016 
separada da sociologia, mas foi reconhecida como parte integrante dela" (STRAUSS,1999, p.24).

\section{ASPECTOS CONCEITUAIS E METODOLÓGICOS DA PSICOLOGIA SOCIAL SOCIOLÓGICA}

Herdeiro da postura teórico-metodológica dos primeiros anos da $E^{18}$ afinado com a pesquisa empírica, com a microssociologia e com as teorias de médio alcance (BLUMER, 1969) -, mas inaugurando uma nova perspectiva de análise social na sociologia, ancorada nos conceitos de interação simbólica e individualismo interacional ${ }^{19}$, o IS emerge como paradigma de afirmação da capacidade dos sujeitos de agirem - fundamentados nas interpretações que fazem da realidade e definindo as situações - na construção e na transformação dos cenários sociais nos quais estão inseridos. Segundo a perspectiva interacionista, o sujeito tem poder de ação e de reação e, embora sofram determinações das estruturas macrossociais que os impelem e impedem, os micro-fundamentos de tais estruturas são formados pelas ações dos atores sociais, os quais por meio de sua ação transformam a ordem social e os macro-sistemas sociais (Cf. BLUMER, 1969; STRAUSS,1999). A capacidade que os sujeitos têm de construir a realidade social, para além de serem construídos por ela, é um ponto fundamental na teoria da ação e dos processos de subjetivação das correntes interacionistas. A perspectiva interacionista desvenda ora atores em atuação (BLUMER, 1969), ora sujeitos em movimentações sociais (STRAUSS, 1999), ora artistas encenando papéis sociais (GOFFMAN, 2011 [1959]).

Desde George H. Mead, a corrente interacionista entende que a sociedade humana fundamenta-se na base do consenso, de sentidos compartilhados, da "rede de negociação", da "ordem negociada" (STRAUSS, 1999), na forma de compreensões e expectativas comuns (BLUMER, 1969). Sendo, portanto, a inter/ação (ação recíproca) o elemento constituinte do comportamento social e das

\footnotetext{
18 Goldenberg (2004) assinala que: "É preciso destacar que a sociologia da Escola de Chicago abriu caminhos para a sociologia como um todo, principalmente no que diz respeito à utilização de métodos e técnicas de pesquisa qualitativa." (p. 30)..

${ }^{19}$ A fase inaugurada por Herbert Blumer (1969) demarca o IS como uma perspectiva mais afinada ao individualismo metodológico. Em fases posteriores, contudo, a corrente interacionista se diversificou em várias ramificações (STRYKER, 1987). Dessa situação emergiram, tanto o interacionismo marxista do conhecido Charles Wright-Mills quanto o interacionismo estrutural de Erving Goffman, o qual é assumido atualmente por Sheldon Stryker (Cf. GONOS, 1977; STRYKER, 2008).
}

R. Inter. Interdisc. INTERthesis, Florianópolis, v.13, n.3, p.101-120 Set.-Dez. 2016 
atitudes humanas. Elemento que aponta para o fato de que os sujeitos não são entes sociais simplesmente assujeitados às circunstâncias, mas capazes de reagir, de confrontar, se reformular, desconstruir, reconstruir e construir os cenários sociais e suas formas de atuação. Como compreende, enfim, um autor interacionista:

\begin{abstract}
[...] a estrutura social e a interação estão intimamente associadas, e também afetam reciprocamente uma à outra (novamente) no tempo. Tratase de uma concepção temporal não só da interação, mas também da própria estrutura, sendo esta última moldada pelos atores por meio da interação (STRAUSS, 1999, p.27).
\end{abstract}

Thomas e Znaniecki - na conhecida nota metodológica de seu "The polish peasant in Europe and America" (1918) - assumem que fazem psicologia social, uma vez que escolheram a interação ou a situação como seu recorte analítico. Pelo que Timasheff (1978) explica que "Thomas escolheu a conduta e depois especialmente a conduta em adaptação, como interesse central de sua teoria sociológica. A ação em uma situação social - sustentou - é o fato social a ser explicado" (p.191, grifo nosso). Deste modo, Thomas e Znanieck são os primeiros proponentes daquilo que Van Velsen (2010 [1967]) e a Escola de Manchester denominaram "análise da situação". Conforme explica Timasheff (1978), para Thomas e Znaniecki, a "situação social" - também denominada "situação total" contém três elementos relacionados entre si: 1) as condições objetivas, que incluem normas de conduta socialmente posta em vigor; 2) as atitudes preexistentes do indivíduo e do grupo; 3) a definição da situação pelo próprio agente, embora este seja influenciado pelo seu grupo de referência.

O fundamental a ser evidenciado até aqui é que a prática sociológica da EC demarcou, já em sua primeira fase, uma forma de pesquisa empírica que influenciou amplamente a psicologia social. O IS, por sua vez, consiste numa psicologia social sociológica por excelência, uma PSOsoc que "enfatiza processos e não estruturas, [...] indeterminação e emergência e não determinação" (BAZILLI et al., 1998, p.31).

\title{
4 CONSIDERAÇÕES FINAIS
}

A aproximação recente da sociologia em relação à psicologia - pelo viés da sociologia em escala individual (MARTUCCELLI, 2002, 2007; GAULEJAC, 2004/2005) - tem se mostrado prolífica em estudos sociológicos recentes. Embora, nos EUA a psicologia social tenha sofrido uma ampla influência da psicologia social psicológica (FARR, 2010), é importante, ressaltar a importância do giro sociológico

R. Inter. Interdisc. INTERthesis, Florianópolis, v.13, n.3, p.101-120 Set.-Dez. 2016 
da psicologia social européia e latino-americana recente, em seu direcionamento para os problemas sociais e para as relações macro-estruturais que os comporta (GONZÁLEZ REY, 2009). Esses dois movimentos resultam em contribuições valiosas para a teoria sociológica e para a psicologia social contemporâneas. O psicologismo e o sociologismo emergem nas análises em que não são considerados aquilo que Gaulejac (2004/2005) devidamente denomina "o irredutível psíquico e o irredutível social" (p.67).

A perspectiva da sociologia interacional - que consiste numa psicologia social sociológica - tornar-se um importante contraponto à psicologia social psicológica ${ }^{20}$. A sociologia, em si mesma, tem muito a ofertar à psicologia social, uma vez que:

Uma psicologia social que não focaliza plenamente a história é uma psicologia cega. Uma preocupação com estilos pessoais. Estratégias, carreiras - em suma, como identidades pessoais - requer uma séria preocupação paralela com identidades partilhadas, ou coletivas, vistas através do tempo (STRAUSS, 1999, p.172).

É relevante lembrar que Theodor Adorno (1903-1969) - sobretudo, em sua fase de produção intelectual nos Estados Unidos - teve um período de incursão na psicologia social, escrevendo trabalhos sobre "as relações entre a sociologia e psicologia" (ADORNO, 1991 [1955]), um estudo sobre a "personalidade autoritária" (ADORNO, et all., 1950), e, por fim, um estudo sobre a "superstição secundária" (ADORNO, 2008 [1970]). David Riesman (1909-2002) escreveu o seu "The lonely crowd" (1950) que é classificado, pelos estudiosos de psicologia social, como um "clássico" da psicologia social sociológica. Deste modo, temos contribuições clássicas de sociólogos, inclusive de correntes alheias ao interacionismo, para a psicologia social sociológica.

São diversas as aproximações contemporâneas da sociologia em relação à PSOsocio. Os trabalhos de Bernard Lahire, Jean-Claude Kaufmann e Vincent de Gaulejac - respectivamente, sociologia do indivíduo, sociologia da identidade e sociologia clínica - são exemplos de tal aproximação. Além desses autores, há o

20 "Existe hoje, um significante contraste na ênfase entre os pontos de vista rivais na Psicologia Social. Um, acentua as formas de conduta no sistema nervoso individual, tal como ocorrem em resposta aos estímulos sociais [...]. O outro coloca ênfase na organização do meio psicossocial, especialmente em seu aspecto mais formal de tradições, convenções, instituições. As formas de conduta que são analisadas por estes pontos de vista são, em última instância, idênticas as formas de conduta individual que resultam de uma situação social de contato [...]. Estes dois extremos estão representados por [Gordon W.] Allport e [Edward] Ross[...]. Por outro lado, o psicólogo social que procede da sociologia, vê o processo de adaptação social a partir da perspectiva das inter-relações sociais objetivas." (BERNARD, 1946 [1926], p. 18). 
trabalho de "sociologia da subjetividade" de Rose ("Inventing our selves" [1998]), os trabalhos recentes do grupo francês "Sociologie de l'imaginaire" liderado por Patrick Legros, os trabalhos sobre "sociologia das emoções", os estudos sociológicos sobre o "conhecimento de si" de Maurice Angers, e, finalmente, os estudos de "representações sociais" de Moscovici $(2000,2011)$, todos esses, consistem em produções da psicologia social sociológica, desdobramentos que, certamente, vão além do IS e que demarcam desenvolvimentos consideráveis de psicologia social sociológica de influência durkheimiana.

R. Inter. Interdisc. INTERthesis, Florianópolis, v.13, n.3, p.101-120 Set.-Dez. 2016 


\title{
SOCIOLOGICAL SOCIAL PSYCHOLOGY: ROUTES, DIRECTIONS AND CONTEMPORANEITY OF A THEORETICAL AND METHODOLOGICAL TRADITION
}

\begin{abstract}
:
The article aims to accomplish the task of revisiting the story of a sociological tradition that was born and developed as a social psychology directed to the study of individuals in interaction and posits a concept of "subject" as a capable and reflective agent, which at all times invents and reinvents himself, peopling the social settings, forming and transforming social reality. The tradition of sociological social psychology begins in France with Tarde and Le Bon and was institutionalized in the United States, consisting of the effective model of sociology practiced in its early years there.
\end{abstract}

Keywords: Sociological Social Psychology. History Of Sociology. History Of Social Psychology. Symbolic Interaction.

\section{PSICOLOGÍA SOCIAL SOCIOLÓGICA: TRAYECTORIAS, DIRECCIONES Y CONTEMPORANEIDAD DE UNA TRADICIÓN TEÓRICA Y METODOLÓGICA}

\section{Resumen:}

En este artículo se pretende llevar a cabo la tarea de revisar la historia de una tradición sociológica que nació y se desarrolló como una psicología social dirigido al estudio de los individuos en interacción y postula un concepto de "sujeto" como agente capaz y reflexivo, que en todo momento inventa y se reinventa, poblando los escenarios sociales, la formación y la transformación de la realidad social. La tradición de la psicología social sociológica comienza en Francia con Tarde y Le Bon y se institucionalizó en los Estados Unidos, constituyéndose en el modelo eficaz de la sociología practicada en sus primeros años en ese ípas. De esta tradición son parte de la Escuela de Chicago y el Interaccionismo Simbólico.

Palabras clave: Psicología Social Sociológica. Historia de la Sociología. Historia de la Psicología Social. Interacción Simbólica. 


\section{REFERÊNCIAS}

ABIB, José Antônio Damásio. Epistemologia pluralizada e história da psicologia. In: Scientiae Studia. São Paulo, v.07, n.02, 2009.

ADORNO, Theodor. W. et all. The authoritarian personality. Studies on prejudice. New York: Harper \& Brothers, 1950.

. De la relación entre sociología y psicología. (1955). In: Actualidad de la filosofia. Barcelona: Paidós, 1991, pp. 135-204

As estrelas descem à Terra. A coluna de astrologia do Los Angeles Times: um estudo sobre superstição secundária. São Paulo: Editora UNESP, 2008 [1970].

ALMEIDA, Angela Maria de Oliveira. Abordagem societal das representações sociais. In: Sociedade e Estado. Brasília, v. 24, n. 3, set./dez., 2009, p. 713-737.

ALVARO, José Luis; GARRIDO, Alicia. Psicologia social: perspectivas psicológicas e sociológicas. São Paulo: McGraw-Hill, 2007.

ÁLVARO-ESTRAMIANA, José Luis; GARRIDO-LUQUE, Alicia. Orígenes sociológicos de la psicología social. In: Revista Española de Investigaciones Sociológicas (REIS). Vol.118, 2007, p.11-16.

BAZILLI, Chirley et al.. Interacionismo simbólico e teoria dos papéis: uma aproximação para a psicologia social. São Paulo: EDUC, 1998.

BLUMER, Herbert. Symbolic interacionism: perspective and method. Englewood Cliffs/New York: Prentice-Hall, 1969.

BOUDON, Raymond; BOURRICAUD, François. Spencer. In:

Dicionário crítico de sociologia. São Paulo: Editora Ática, 1993b [1982], p.535543. 1993.

BRAMSON, Leon. Os conceitos americano e europeu de comportamento coletivo. In: . O conteúdo político da sociologia. Rio de Janeiro/São Paulo: Editora Fundo de Cultura, 1963, p.59-84. 
CHAVES, Sandra Souza da Silva; BORGES, Lívia de Oliveira. Um bom caminho para adentrar a psicologia social. (Resenha). In: Estudos de Psicologia. Vol.10, n.02, 2005, p. 321-323.

CLARK, Terry. The structure and functions of a Research Institute: The Année Sociologique. In: Archives Européennes de sociologie. N.01, v. IX, 1968

CONSOLIM, Márcia Cristina. Crítica da razão acadêmica: campo das ciências sociais "livres" e psicologia social francesa no fim do século XIX. (Tese de doutorado não publicada). Faculdade Filosofia, Letras e Ciências Humanas da Universidade de São Paulo. São Paulo: USP, 2007.

Émile Durkheim e Gabriel Tarde: aspectos teóricos de um debate histórico (1893-1904). In: História: questões \& debates. Curitiba, n. 53, jul./dez., 2010, p. 39-65.

COSER, Lewis A. Tendências americanas. In: BOTTOMORE, Tom e NISBET, Robert. História da análise sociológica. Rio de Janeiro: Zahar Editores, 1980, p. 379-420.

COULON, Alain. A Escola de Chicago. Campinas, SP: Papirus Editora, 1995.

DURKHEIM, Émile. Representações individuais e representações coletivas. (1898). In: . Sociologia e filosofia. São Paulo: Martin Claret, 2009 [1924].

ESTRAMIANA, José Luis Álvaro et al. Introducción a la psicologia social sociológica. Barcelona: Editorial UOC, 2007.

EUFRASIO, Mário A. Estrutura urbana e ecologia humana: a escola sociológica de Chicago (1915-1940). São Paulo: Editora 34, 1999.

FARR, Roberto M. As raízes da psicologia social moderna. (9. ed.). Rio de Janeiro: Vozes, 2010.

GAULEJAC, Vincent de. O âmago da discussão: da sociologia do indivíduo à sociologia do sujeito. In: Revista Cronos. Natal-RN, v. 05/06, n. 01/02, jan./dez., 2004/2005, p. 47-58. 
GOFFMAN, Erving. A representação do eu na vida cotidiana. Petrópolis, RJ:

Editora Vozes, 2011 [1959].

GOLDENBERG, Mirian. A arte de pesquisar: como fazer pesquisa qualitativa em Ciências Sociais. (8. ed.). Rio de Janeiro: Record, 2004.

GONOS, George. "Situation" versus "Frame": the "Interactionist" and the "Structuralist" Analyses of Everyday Life. In: American Sociological Review. Vol. 42, n.06, december, 1977, p. 854-867.

GONZÁLEZ REY, Fernando. O social na psicologia e a psicologia social: a emergência do sujeito. (2. ed.) Petrópolis, RJ: Editora Vozes, 2009.

JACÓ-VILELA, Ana. M.; FERREIRA, Arthur Arruda L.; PORTUGAL, Francisco. T. (Org.). História da psicologia: rumos e percursos. Rio de Janeiro: NAU Editora, 2006.

JAMES, Willian. Apelo para que a psicologia seja uma ciência natural. In: Scientiae Studia. São Paulo, v. 7, n. 2, 2009, [1892], p. 317-24.

MARTUCCELLI, Danilo. Gramáticas del individuo. Buenos Aires: Losada, 2002. LOM, 2007.

Cambio de rumbo. La sociedad a escala del individuo. Santiago de Chile:

MENDRAS, Henry. Princípios de sociologia: uma iniciação à análise sociológica. Rio de Janeiro: Zahar Editores, 1975.

MOSCOVICI, Serge. Social representations: explorations in social psychology. [Gerard Duveen - Ed. Nova York: Polity Press/Blackwell Publishers, 2000.

Vozes, 2011.

A invenção da sociedade: sociologia e psicologia. Petrópolis, RJ: Editora

MUNNÉ, Frederic. La construcción de la psicología social como ciencia teórica. PPU. Barcelona. 1993.

. Entre el individuo y la sociedad. Marcos y teorías actuales sobre el comportamiento interpersonal. Barcelona: E.U.B., 1996. 
ORTIZ, Renato. Durkheim: arquiteto e herói fundador. In: Revista Brasileira de Ciências Sociais. Vol.04, n.11, outubro, 1989, p.05-22.

PARSONS, Talcott. The structure of social action: a study in social theory with special reference to a group of recent European writers (Vol. I \& II). New Yrk : Free Press, 1949.

PORTUGAL, Francisco. T. Psicologia social em George Mead, na Escola de Chicago e em Erving Goffman. In: JACÓ-VILELA, Ana. M.; FERREIRA, Arthur Arruda L.; PORTUGAL, Francisco. T. (Org.). História da psicologia: rumos e percursos. Rio de Janeiro: NAU Editora, 2006, p.463-472.

STRAUSS, Anselm. L. Espelhos e máscaras: a busca da identidade. São Paulo: Edusp, 1999

STRYKER, Sheldon. The vitalization of symbolic interactionism. In: Social Psychology Quarterly. Vol. 50, n.01, mar., 1987, p. 83-94.

. From Mead to a structural symbolic interactionism and beyond. In: Annual Review of Sociology. Vol.34, 2008, p. 15-31

TIMASHEFF, Nicholas S. Teoria sociológica. Rio de Janeiro: Zahar Editores, 1978.

VARGAS, Eduardo Viana. Antes Tarde do que nunca: Gabriel Tarde e emergência das ciências sociais. Belo Horizonte: Contra Capa, 2000.

Artigo:

Recebido em 18 de Janeiro de 2016

Aceito em 31 de Julho de 2016

R. Inter. Interdisc. INTERthesis, Florianópolis, v.13, n.3, p.101-120 Set.-Dez. 2016 